\title{
VHF-DEPOSITED a-SiC:H ALLOYS FOR HIGH-BANDGAP SOLAR CELLS: COMBINING HIGH VOC AND REASONABLE STABILITY
}

\author{
R. PLATZ, D. FISCHER AND A. SHAH \\ Institut de Microtechnique, Université de Neuchâtel, Rue A.-L. Breguet 2, CH-2000 Neuchâtel, \\ Switzerland
}

\begin{abstract}
The material properties of a-SiC:H alloys deposited by VHFGD are studied, with a special emphasis on the effect of hydrogen dilution of the plasma on layer quality. By incorporating these layers into $\mathrm{p}-\mathrm{i}-\mathrm{n}$ solar cells the authors compare layer properties and cell performance. Special attention is paid to the stability of the solar cells against light soaking. Furthermore, the authors show that the insertion of a buffer layer can, also in the case of entirely a-SiC:H cells, lead to a substantial increase of $\mathrm{V}_{\mathrm{oc}}$. A reasonable stability of these cells is maintained by an appropriate doping of the buffer layers.
\end{abstract}

\section{INTRODUCTION}

The bandgap of a-Si:H is increased by carbon alloying. A-SiC:H based materials and cells have thus been investigated intensively in the past. While high-voltage a-SiC:H cells have been demonstrated $^{1}$, those cells are still not applied in today's best stable a-Si:H stacked cell modules $^{2}$, because of their insufficient stability.

From work on a-Si:H cells, the stability is known to be determined by both the film quality and the device structure. In the present paper we address first the film quality issue in a study combining the proven method of hydrogen plasma dilution with that of VHF plasma excitation, so as to thereby optimise a-SiC:H film properties. In the second part, we apply these films to high-voltage $\mathrm{p}-\mathrm{i}-\mathrm{n}$ cells, emphasising, in particular, the role of $\mathrm{p}$-i buffer layers, which have already been shown to play a crucial role in a-Si:H solar cell stability.

\section{MATERIAL STUDY}

\section{Experimental}

Intrinsic layers of amorphous hydrogenated silicon carbon alloys were deposited from silane $\left(\mathrm{SiH}_{4}\right)$ and methane $\left(\mathrm{CH}_{4}\right)$ as feedstock gases, in a single chamber reactor using the very high frequency glow discharge technique (VHFGD) at $70 \mathrm{MHz}$. The RF input-power of $30 \mathrm{~mW} / \mathrm{cm}^{2}$ (for some films, $60 \mathrm{~mW} / \mathrm{cm}^{2}$ ) is coupled capacitively to the plasma. The pressure during deposition was always 0.4mbar. Dow Corning 7059 glass and single-crystal Si-wafers (for infrared measurements) were used as substrates. The film thickness was measured using an $\alpha$ Step profiler. As a measure for the bandgap energy, we determined $\mathrm{E}_{04}\left[\alpha\left(\mathrm{E}_{04}\right)=10^{4} \mathrm{~cm}^{-1}\right]$ and $E_{\text {tauc }}$ (extrapolation of $\sqrt{\alpha E}$ ) from the evaluation of visible/UV transmission and reflection spectra. The Urbach energy was determined by PDS. Absolute values were obtained by calibrating the spectra in the high-energy range to the (absolute) absorption spectra from transmission/reflection measurements. The microstructure factor of the samples as well as the hydrogen content were determined evaluating IR absorption spectra. Conductivity measurements were executed using coplanar aluminium contacts; the samples were heated up to $180^{\circ} \mathrm{C}$ and afterwards slowly cooled down. Photoconductivity was measured under $100 \mathrm{~mW} / \mathrm{cm}^{2}$ illumination.

Hydrogen dilution (dil. $\left.=\left[\mathrm{H}_{2}\right] /\left(\left[\mathrm{SiH}_{4}\right]+\left[\mathrm{CH}_{4}\right]\right)\right)$ was varied from zero dilution to a dilution of 20 , and the methane fraction $\left[\mathrm{CH}_{4}\right] /\left(\left[\mathrm{SiH}_{4}\right]+\left[\mathrm{CH}_{4}\right]\right)$ was varied from 0 to $90 \%$. Gas fluxes were between 5 and $20 \mathrm{sccm}$ for $\mathrm{SiH}_{4}$ and $\mathrm{CH}_{4}$, and up to 100 sccm for $\mathrm{H}_{2}$. 


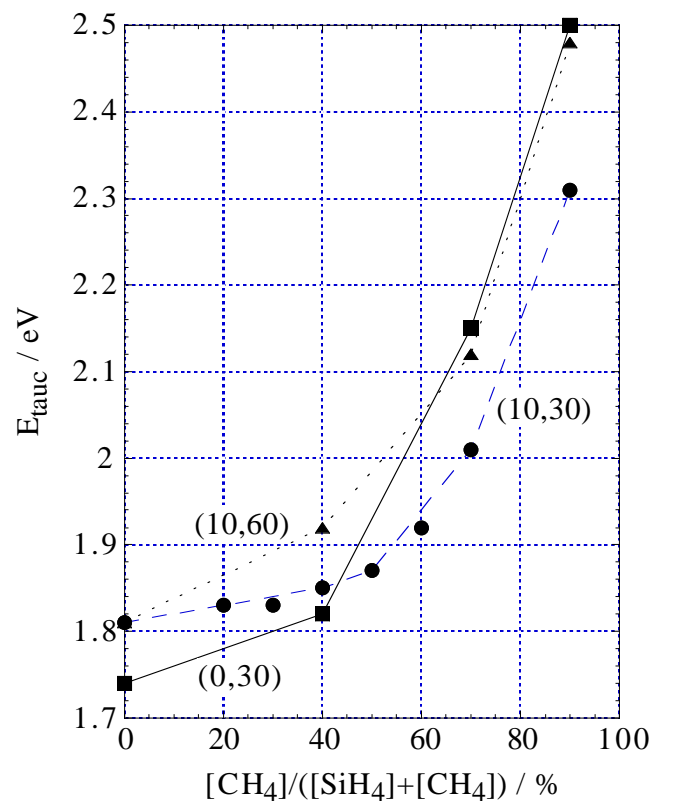

Fig.1: Optical gap for different methane contents in the gas phase. The first number in brackets indicates the dilution, the second the power density in $\mathrm{mW} / \mathrm{cm}^{2}$.

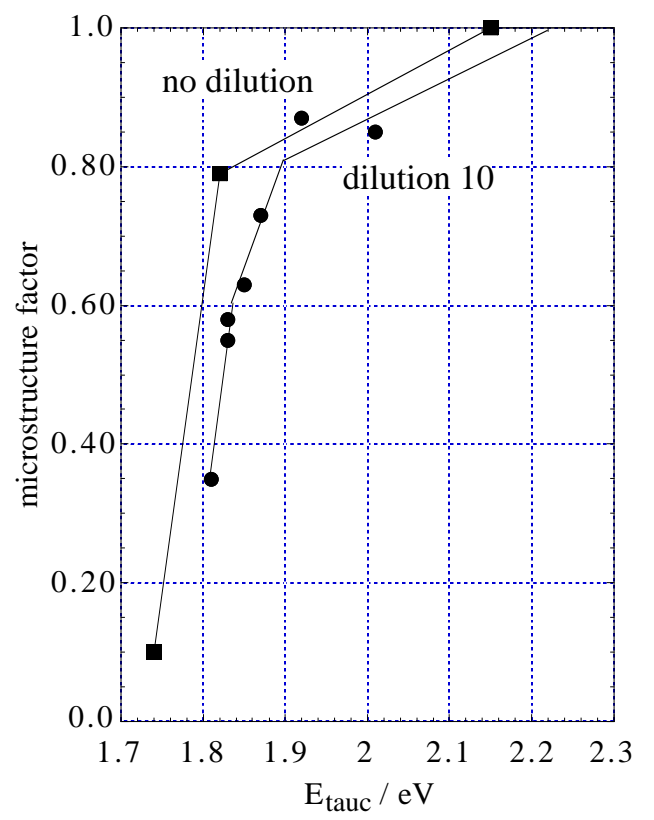

Fig.2: Microstructure factor $\left(=\int 2100\right.$ $\left./\left(\int 2000+\int 2100\right)\right)$ for undiluted samples and samples deposited with a dilution of 10 $\left(\right.$ dil. $\left.=\left[\mathrm{H}_{2}\right] /\left(\left[\mathrm{SiH}_{4}\right]+\left[\mathrm{CH}_{4}\right]\right)\right)$ as a function of the bandgap. $1000 \mathrm{~cm}^{-1}$ with time. Samples prepared with the same amount of $\mathrm{CH}_{4}$ and hydrogen dilution do not show this feature. For samples prepared at lower $\mathrm{CH}_{4}$ flows we found no oxidation, even without dilution, e.g., for a $80 \% \mathrm{CH}_{4}$-sample without dilution, no oxidation was observed. This is a further fact indicating that hydrogen dilution of the plasma results in more dense film structures.

Investigating the influence of methane content in the gas phase on the bandgap, we prepared films with different $\mathrm{CH}_{4}$ to $\mathrm{CH}_{4}+\mathrm{SiH}_{4}$ ratios, ranging from 0 (pure silicon films) to $90 \%$. Fig. 1 shows the results; for all deposition conditions the bandgap energy increases with an increase in the amount of methane in the gas phase. Former publications of our group ${ }^{3}$ indicated that the VHF-deposition technique is favourable for carbon incorporation in the layers. We prepared a series at different dilutions, some samples being deposited at higher power $\left(60 \mathrm{~mW} / \mathrm{cm}^{2}\right)$ to make sure that the obtained films are purely amorphous as VHF deposition under hydrogen dilution and with low power is relatively favourable to microcrystalline growth ${ }^{4}$.

Up to about $40 \% \mathrm{CH}_{4}$, the increase of the gap is relatively moderate; for higher amounts of methane one observes a rapid increase of the gap. An interesting feature is that the gap of the samples deposited from pure $\mathrm{SiH}_{4}$ without $\mathrm{CH}_{4}$ under hydrogen dilution is shifted from $1.74 \mathrm{eV}$ to about $1.8 \mathrm{eV}$. Hydrogen dilution yields somewhat smaller gaps for a $\mathrm{CH}_{4}$ content $>40 \%$, as compared to undiluted samples or samples deposited with enhanced power. These results are quite similar to those of other groups ${ }^{5,6}$ depositing at $13.56 \mathrm{MHz}$.

Hydrogen dilution of the plasma was in the past found to be advantageous for the film properties of RF $(13.56 \mathrm{MHz})$ deposited films ${ }^{7}$. The dilution of the plasma is believed to enhance the surface mobility during growth and, therefore, the quality of the layers, because a denser structure with less microvoids is obtained. We prepared samples with $40 \%$ methane in the gas phase and dilutions of 0,5 , 10 and 20. Infrared absorption spectra clearly demonstrate that the microstructure factor defined as the ratio of the integrated absorption peak at $2100 \mathrm{~cm}^{-1}\left(\mathrm{SiH}_{2}\right)$ to the sum of the $2000 \mathrm{~cm}^{-1}(\mathrm{SiH})$ and the $2100 \mathrm{~cm}^{-1}$ peaks improves under increasing hydrogen dilution. However, for samples with a high gap, i.e. deposited with large $\mathrm{CH}_{4}$-fractions in the gas phase, hydrogen dilution cannot preserve the microstructure factor from rapid deterioration (Fig.2).

For undiluted samples with a high carbon content we observed a post-deposition oxidation of the layers as already reported in ref.8. A sample deposited with $90 \%$ methane and no $\mathrm{H}_{2}$ dilution shows a strong increase of the SiO IR absorption peak at about

\section{$\underline{\text { Results and Discussion }}$}




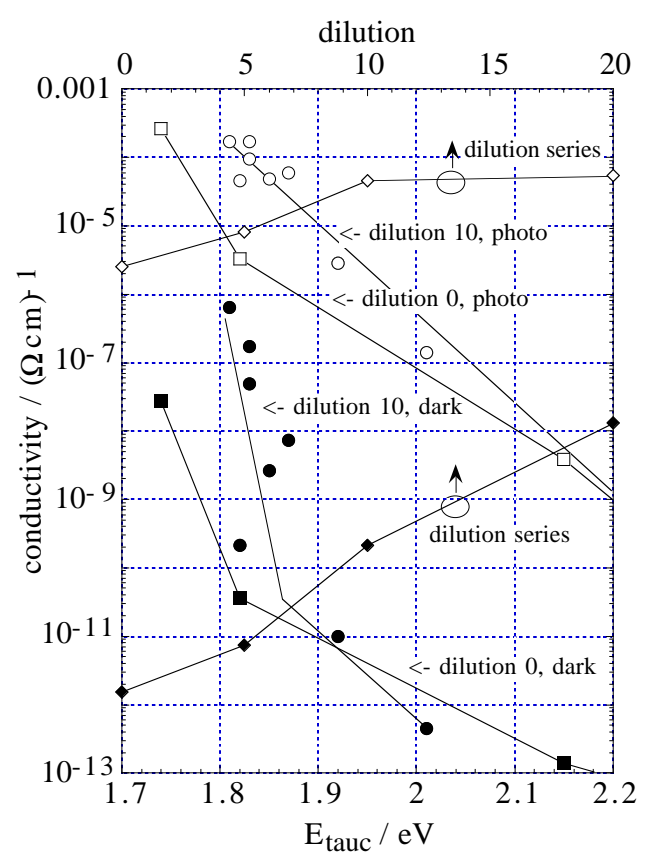

Fig.3: Photo (open) and dark (filled symbols) conductivities as a function of the bandgap energy. We show two series, one deposited without any hydrogen dilution, the other with a hydrogen dilution of 10 . The other curves (open diamonds for photo and filled diamonds for dark conductivities) show samples for a fixed value of $40 \% \mathrm{CH}_{4}$ but different dilutions.

bserve an increase of th dilurion dilution prevents the Urbach energy from a too strong increase; for samples prepared with a dilution of 10, the Urbach energy remains, in contrast to undiluted samples, well below $70 \mathrm{meV}$ up to a bandgap energy of about $2.1 \mathrm{eV}$.

The deposition rate is remarkably higher for our VHF deposition system than for conventional RF systems. In contrast to RF deposition, we observe an increase of the deposition rate with increasing methane flow. For an undiluted plasma and $30 \mathrm{~mW} / \mathrm{cm}^{2}$ power, we found the deposition rate for $40 \% \mathrm{CH}_{4}$ to be $8.6 \AA / s$. Hydrogen dilution strongly reduces the deposition rate, for a dilution of 10 and again for $40 \% \mathrm{CH}_{4}$, we attain $1.6 \AA / s$ for otherwise same conditions. For diluted plasmas, the deposition rate decreases with increasing methane content in the gas.

As a conclusion of this material study, we would like to point out that for the VHFdeposition technique, also, hydrogen dilution can remarkably improve the material quality for moderate carbon contents (i.e. moderate bandgap energies). If the dilution is too high, layers show increased conductivity, especially for low carbon contents. This could be either due to the onset of microcrystalline growth ${ }^{9}$, or also due to enhanced impurity incorporation for low deposition rates. For samples with a gap larger than about $2 \mathrm{eV}$ the material properties deteriorate very rapidly, even with a strong hydrogen dilution. We therefore believe a material deposited with about $40 \% \mathrm{CH}_{4}$ and a dilution of 10 to be a promising candidate for the i-layer in a p-i-n solar cell. However, it has first to be shown that better film properties actually result in better cell performances and enhanced stability: this will be the topic of the next section.

\section{P-I-N SOLAR CELLS WITH a-SiC:H ABSORBING LAYER}

In a next step, some of the a-SiC:H i-layers described above were incorporated as i-layer in $\mathrm{p}-\mathrm{i}-\mathrm{n}$ solar cells. The cells were made in the same single chamber reactor as already used for the material study, guaranteeing, thus, the same material for both parts of the study. We used a shutter to cover the substrate during the deposition of an intrinsic dummy layer after the p-layer 
to suppress boron contamination of the i-layer. Degradation was systematically investigated, keeping in mind that silicon carbon alloys are specially sensitive to degradation and that any reasonable cell optimisation has to compare stabilised results.

A comparison of cells made from pure silane with a dilution of $10\left(\mathrm{E}_{\mathrm{g}}=1.81 \mathrm{eV}\right.$, Fig. 1$)$ and without dilution $\left(\mathrm{E}_{\mathrm{g}}=1.74 \mathrm{eV}\right)$ and of a cell made with $40 \% \mathrm{CH}_{4}$ and a dilution of 10 $\left(E_{g}=1.85 \mathrm{eV}\right)$, indicates a clear influence of the enhanced gap on the open circuit voltage and on the absorption as measured by spectral response measurements. Nevertheless, the value of $\mathrm{V}_{\mathrm{oc}}$ follows an increase in the gap of the i-layer only up to a certain amount. For even higher gaps, $\mathrm{V}_{\mathrm{oc}}$ remains about the same. This is thought to be due to the doped layers which are the same as those used for standard a-Si:H cells and/or due to the drastic deterioration of the material properties enhancing recombination and thereby limiting $\mathrm{V}_{\mathrm{oc}}$. We should like to note that all these cells were deposited on NSG textured substrates. Performing the same deposition on flat substrates we observe $\mathrm{V}_{\mathrm{oc}}$ values which are about $20-30 \mathrm{mV}$ higher.

The results indicate that the increase of the gap for silicon carbon alloys can be both an effect of different material structure due to enhanced hydrogen incorporation under dilution and incorporation of carbon. We would like to note that the diluted a-Si:H cell was made at a standard deposition temperature of $220^{\circ} \mathrm{C}$. A certain enhancement of $\mathrm{V}_{\mathrm{oc}}$ was already achieved only by $\mathrm{H}_{2}$ dilution of the silane plasma. For further increase of $\mathrm{V}_{\mathrm{oc}}$, addition of methane to the plasma or low-temperature deposition of amorphous silicon is necessary.

In order to compare the performance and stability of the three cell types mentioned, we deposited a small series of $200 \mathrm{~nm}$ thick cells from undiluted/diluted $\mathrm{SiH}_{4}$ and undiluted/diluted $\mathrm{SiH}_{4}+\mathrm{CH}_{4}(40 \%)$ as well as a $100 \mathrm{~nm}$ thick a-SiC:H cell from a diluted plasma. The doped layers were the same for all cells. A $70 \% \mathrm{CH}_{4}$ (dil. 10) buffer layer of $10 \mathrm{~nm}$ thickness was added to a $100 \mathrm{~nm}$ diluted a-SiC:H cell in order to observe its influence on the cell performance and stability. The following table 1 shows the results in the initial state as well as the effect of degradation $\left(100 \mathrm{~mW} / \mathrm{cm}^{2}\right.$ sodium lamp at about $\left.50^{\circ} \mathrm{C}\right)$.

\begin{tabular}{|l|l|l|l|l|l|l|l|l|l|}
\hline $\begin{array}{l}\text { thickness } \\
\text { i-layer }\end{array}$ & type & \multicolumn{2}{l|}{ initial } & \multicolumn{2}{l|}{ 280h } & \multicolumn{2}{l|}{ relative degr. } \\
& & Eg/eV & Voc/V & FF/\% & Voc/V & FF/\% & Voc & FF \\
\hline $200 \mathrm{~nm}$ & a-Si:H undiluted & 1.74 & 0.82 & 66.4 & 0.82 & 59.0 & 0.00 & 0.11 \\
\hline & a-Si:H (dil.10) & 1.81 & 0.89 & 62.5 & 0.88 & 54.5 & 0.01 & 0.13 \\
\hline & a-SiC:H undiluted & 1.82 & 0.92 & 62.7 & 0.82 & 31.8 & 0.11 & 0.49 \\
\hline & a-SiC:H (dil.10) & 1.85 & 0.95 & 56.0 & 0.87 & 41.7 & 0.08 & 0.25 \\
\hline 100nm & a-SiC:H (dil.10) & 1.85 & 0.95 & 68.7 & 0.90 & 54.1 & 0.05 & 0.21 \\
\hline & $\begin{array}{l}\text { a-SiC:H (dil.10) with buffer } \\
\text { (dil.10). }\end{array}$ & $2.02 /$ & 0.98 & 61.7 & 0.89 & 38.2 & 0.09 & 0.38 \\
\hline
\end{tabular}

Table 1: Initial performance and influence of degradation for different p-i-n solar cells made from diluted and undiluted $\mathrm{SiH}_{4}$ and $\mathrm{SiH}_{4}(60 \%)+\mathrm{CH}_{4}(40 \%)$.

One observes that cells deposited from undiluted $\mathrm{SiH}_{4}+\mathrm{CH}_{4}$ have a slightly lower $\mathrm{V}_{\mathrm{oc}}$ in the initial state, when compared to cells made from a diluted plasma. Clearly, the undiluted cell degrades much stronger than the diluted one. Mainly the fill factor decreases to unacceptably low values. But also $\mathrm{V}_{\mathrm{oc}}$ suffers from strong degradation. In contrast to that, the $200 \mathrm{~nm}$ thick diluted a-SiC:H-cell degrades much less, but still to an amount which is not supportable for solar cell applications. For the same i-layer material, however, a cell with 100nm i-layer thickness degrades much less. As a-SiC:H cells are to be applied as top cells in tandem or triple structures, a realistic thickness will indeed be rather like $100 \mathrm{~nm}$ or even less. Furthermore, degradation will be less pronounced as light which is not absorbed in the top cell will not be reflected as in the case for these test cells which were made with a highly reflective ITO/Ag back reflector. The cell deposited from diluted $\mathrm{SiH}_{4}$ suffers no degradation of $\mathrm{V}_{\mathrm{oc}}$.

In non-alloyed a-Si:H cells, it is well known that buffer layers can enhance $\mathrm{V}_{\mathrm{oc}}$. In our experiments, we achieve for $\mathrm{V}_{\mathrm{oc}}$ a value of $980 \mathrm{mV}$, with a buffer layer $\left(70 \% \mathrm{CH}_{4}\right.$, dilution 10) representing an increase of $30-40 \mathrm{mV}$. However, after degradation no gain in $\mathrm{V}_{\mathrm{oc}}$ (due to the buffer layer) is left, and the fill factor suffers from strong deterioration. Spectral response (Fig.5) 


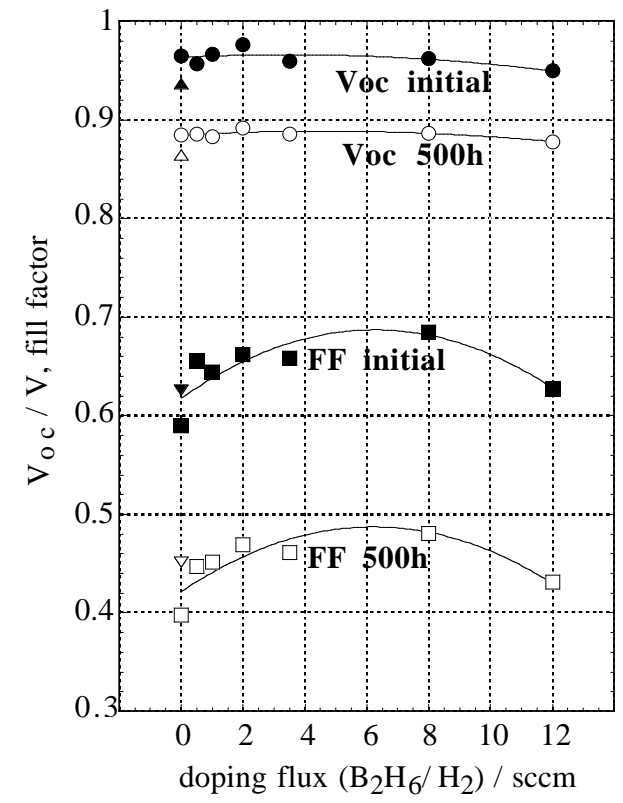

Fig.4: Dependence of fill factor and $\mathrm{V}_{\mathrm{Oc}}$ on the doping concentration of the buffer layer before and after degradation and comparison to a cell without buffer layer (triangles).

(undoped) buffer one can enhance the $\mathrm{V}_{\mathrm{oc}}$, at the same time the FF decreases slightly. Doping of the buffer layer has nearly no influence on the voltage, whereas the fill factor increases for slight doping and seems to decrease again for higher doping rates. For our system we observe an optimal value of about 4$8 \mathrm{sccm} \mathrm{B} \mathrm{H}_{6}\left(500 \mathrm{ppm}\right.$ in $\left.\mathrm{H}_{2}\right)$.

Spectral response measurements give a clear indication of a changed field profile in the cell after insertion of a buffer layer. Fig.5 shows the spectral response data for a "standard" cell without buffer layer, and for cells with an undoped and a $3.5 \mathrm{sccm}$ boron-doped buffer layer. The saturated spectral response curves $(-3 \mathrm{~V})$ are given as a measure for the absorption and are quite similar for all three cells. As already noted, one observes in the initial state a significant loss of collection efficiency in the red range, for the case of the undoped buffer. This effect is counteracted by boron-doping of the buffer. In the blue range one observes some decrease of the collection efficiency due to the doping of the buffer layer. The main effect appears after degradation, when the collection efficiency of the cell with an undoped buffer suffers from a strong decrease in the red range, this being certainly due to a strong increase in the density of positively charged defects in the buffer and in the resulting field distortion: by a slight doping of the buffer, this positive space charge is compensated, and thereby the electric field is maintained, resulting in a far better red response.

Applying the above described results to a deposition system with a loadlock (this system being

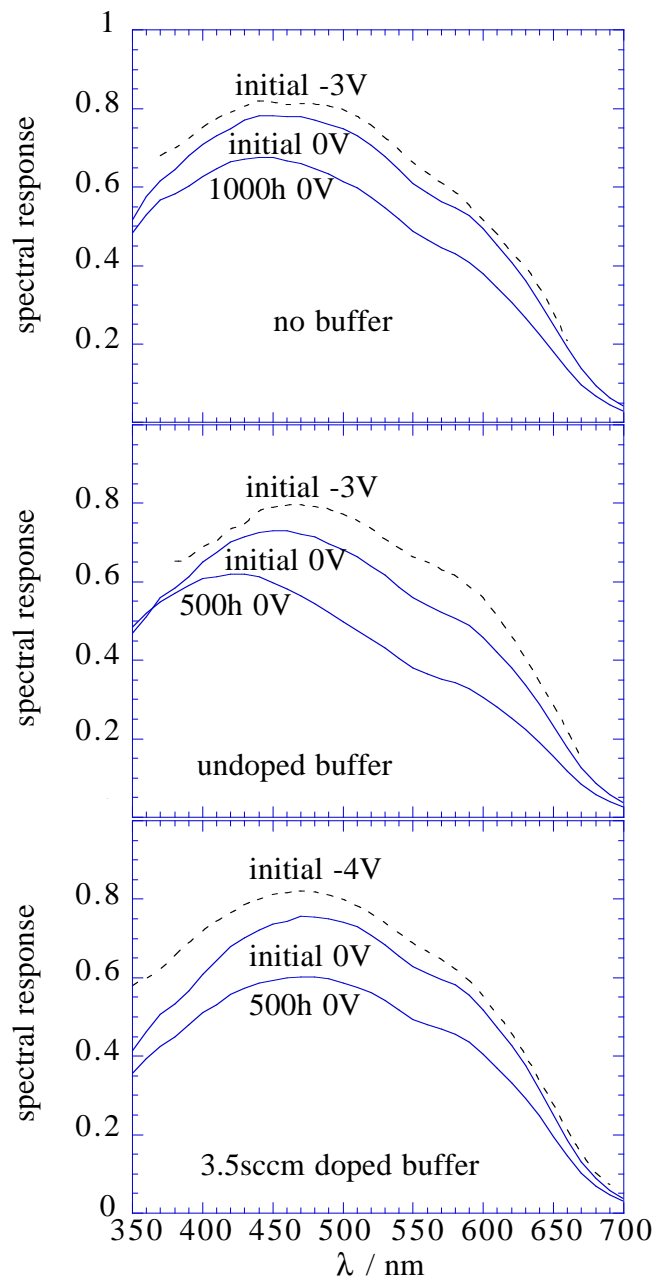

Fig.5: Spectral response data in the initial and degraded state for undoped and slightly borondoped buffers as well as for a "standard" cell without buffer layer. 
more appropriate for depositing solar cells) we achieved a $V_{o c}$ value of $0.97 \mathrm{~V}$ with a fill factor of $67 \%$, for a $1000 \AA$ thick cell without buffer layer on Asahi U-type TCO. Inserting a 60\% $\mathrm{CH}_{4}$ buffer layer into the cells, we could increase the $\mathrm{V}_{\mathrm{oc}}$ to $1.01 \mathrm{~V}$ at $65 \%$ fill factor (for an undoped buffer) and $1.01 \mathrm{~V} / 69 \%$ for a slightly borondoped buffer, thereby confirming the above analysis. Fig.6 shows the degradation kinetics for those cells and, for comparison, that of a cell without buffer. There is still some $\mathrm{V}_{\mathrm{oc}}$ degradation; however, we were able to show that, for a-SiC:H cells also, the application of a buffer layer with an appropriate doping can enhance the voltage. The fill factor degradation can be kept at values comparable to those of cells without a buffer layer.

\section{CONCLUSIONS}

Using the VHF deposition technique for a-SiC:H alloys, one can significantly improve the material properties at moderate carbon contents by a hydrogen dilution of the plasma. The insertion of these materials, deposited at high rates, into solar cells leads to satisfactory cell performance.

The application of a buffer layer in a-SiC:H cells enhances $\mathrm{V}_{\mathrm{oc}}$ by $30-40 \mathrm{mV}$, but results in a lower stability due to the collapse of the inner electrical field after degradation.

By a slight boron-doping of the buffer layer, this effect can be counteracted, and a higher electrical field in the bulk is maintained after degradation, resulting in a higher stabilised fill factor.

A p-b-i-n solar cell with an i-layer thickness of $1000 \AA$ and a boron-doped buffer yields a value of $\mathrm{V}_{\mathrm{oc}}$ over $1 \mathrm{~V}$ and a fill factor of $69 \%$.

\section{ACKNOWLEDGEMENTS}

The authors wish to thank S. Dubail for his technical support. Financial support by CERS (project 2745.1) and OFEN (project EF REN(93)032) is gratefully acknowledged.

\section{REFERENCES}

$1 \quad$ Y.-M. Li et al., Proc. 23rd IEEE PVSC (1993) 850.

2 S. Guha et al., MRS Symp. Proc. 336 (1994) 645.

3 G. Crovini et al., MRS Symp. Proc. 336 (1994) 481.

$4 \quad$ K. Prasad et al., MRS Symp. Proc. 219 (1991) 469.

$5 \quad$ R. Galloni et al., MRS Symp. Proc. 336 (1994) 517.

6 B. Rech et al., Proc. 12th EC PVSEC, Amsterdam 1994, 1245.

7 A. Matsuda et al., J. Appl. Phys. 60 (11) 1986, 4025.

$8 \quad$ K. Eberhardt et al., MRS Symp. Proc. 258 (1992) 673.

9 S. Ghosh et al., J. Appl. Phys. 71 (10) 1992, 5205.

10 B. Rech et al., Proc. 1st WCPEC, Hawaii 1994, to be published. 